\title{
Vertical Recycling Aquatic System for Internet-of-Things-based Smart Fish Farm
}

\author{
Amaranthvarma Angani, Jun Charn Lee, and Kyoo Jae Shin ${ }^{* *}$ \\ Department of ICT Creative Design, Busan University of Foreign Studies, BUFS \\ 65, Geumsaem-ro 485 Beon-gil, Geumjeong-gu, Busan 46234, Republic of Korea
}

(Received February 28, 2019; accepted August 26, 2019)

Keywords: IoT-based smart fish farm, vertical recirculating aquatic system, automatic fluid flow control system, sensors, water quantity

This paper is about the design, analysis, and installation of an Internet of Things (IoT)-based smart fish farm with a water recycling system installed to prevent the wastage of water. Sensors play a key role in improving the water quality in a smart fish farm with an automatic controlling system. In this aquatic system, the water flow process is regulated by a proportionalintegrator-derivative (PID) controller along with water-level ultrasonic, water temperature, dissolved oxygen (DO) concentration, and $\mathrm{pH}$ sensors. Sensor data are collected and stored in the lab server as big data. For automatic operation, these sensors send feedback to the PID controller to operate the fish farm within the specified range of operating conditions. To verify the performance of this designed system, field tests were conducted at the Future Creative Technology Research Institute of Busan University of Foreign Studies and at the Jangsucheon Ltd. farm on Ganghwa Island. This system was tested and successfully installed with good results.

\section{Introduction}

Nowadays, aquaculture is an important means of farming that provides food resources for humans, and research on smart fish farm systems is being carried out towards the mass production of healthy fish for eating. Generally, fish farms are located in areas with a large quantity of water available such as rivers and oceans. There are two methods of water circulation in aquaculture. The first is the natural water circulation aquaculture method and the second is the recirculating aquaculture system (RAS) method. The natural water circulation system has a simple pump and a basic control system for introducing and discharging natural supply water. In the first method, contaminated water is directly discharged into the sea or river, causing water pollution. ${ }^{(1)}$

This problem of water pollution can be rectified by the RAS method. In this method, contaminated water is recirculated to physical and biological filters to remove the sludge and purify the water. The purified water is processed for it to have the appropriate temperature and

\footnotetext{
*Corresponding author: e-mail: amaranth.angani@gmail.com

${ }^{* *}$ Corresponding author: e-mail: kyoojae@bufs.ac.kr

https://doi.org/10.18494/SAM.2019.2366
} 
dissolved oxygen (DO) concentration and then supplied back to the aquarium tanks. Therefore, the RAS method provides the optimal water level, temperature, DO concentration, and $\mathrm{pH}$ for the fish to live in the water tank. Recently, there has been a tendency to apply the RAS method, which filters the sludge from the water and reuses the water, in aquaculture on the land. ${ }^{(2)}$

For the fish farm discussed in this paper, the Internet of Things (IoT) is utilized as an interactive embedded technology between the sensor-based farm and automatic control devices. This technology can be used as an integrated control network for smart fish farms, which is realized by adopting efficient wireless protocols, improved sensors, and precision processors. ${ }^{(3)}$ The goal of this study is not only to reduce human effort in managing fish farms, but also to improve the production of healthy fish, the efficiency of automated control, and the safety of edible fish. The proposed IoT-based smart fish farm system will bring big changes to society regarding the production of healthy and protein-rich fish, productivity improvement, and the advanced industrialization of aquaculture with automatic control of water level, temperature, DO concentration, and $\mathrm{pH}$ obtained from sensor data and internet technologies. ${ }^{(4)}$

To implement the IoT-based smart fish farm, water temperature, $\mathrm{pH}, \mathrm{DO}$ concentration, and ultrasonic sensors for water volume control are used as shown in Fig. 1. The sensor signals are input to the signal conditioner and sent to the microcomputer and computer. The transmitted signal sends feedback to perform automatic control. The proposed RAS scheme is shown in Fig. 1. Generally, an aquaculture tank is installed horizontally on land whereas our proposed model is the vertically assembled water tank structure shown in Fig. 1. The main purpose of this proposed system is to increase the production of healthy fish by reducing the space required. The proposed farm consists of aquarium tanks 1 and 2, a balancing tank, and an RAS tank. Aquarium tanks 1 and 2 are used to cultivate eels with less water and the RAS tank is for purifying contaminated water from aquarium tanks 1 and 2 by physical and biological filtration. The filtered water is fed to a balancing tank to supply water at the required temperature and DO concentration suitable for fish growth. After reaching the specified operating range conditions the water is recirculated to aquarium tanks 1 and $2 .^{(5)}$

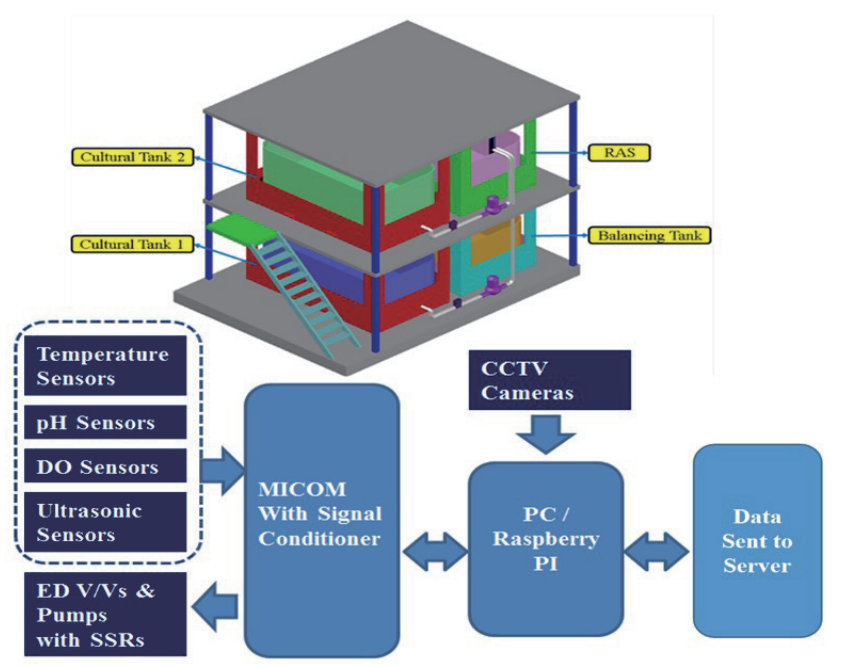

Fig. 1. (Color online) Design of smart fish farm and sensor data collection system. 
The proposed circulation filtration system can supply water and measure the DO concentration, temperature, $\mathrm{pH}$, and level of the supplied water, and automatically control water circulation. This method is very important for the purification of water. Therefore, the proposed circulation filtration method can control the flow of water and maintain a suitable DO concentration and $\mathrm{pH}$ by removing the sludge and by automatically controlling the water pump and electric valve by using a sensor and microcomputer based on IoT. In addition, the CCTV cameras are installed in each tank to observe the growth of the fish and provide the function of recording and analyzing the fish growth when controlling the quantity of fish. ${ }^{(6,7)}$

\section{Design of Vertical Recycling Aquatic System (VRAS)}

Smart farms are intelligent aquaculture systems with an enormous supply of water. These fish farm systems can automatically collect water quality data and send them to a server to accumulate big data. The measured data can be stored on the server in real time and used to send feedback to an electric valve that can be controlled automatically.

This aquaculture system makes it easy to control the supply of a large quantity of water of good quality. The proposed vertical water tank shown in Fig. 2 can be used as a mainframe to easily make a vertical structure. The specifications of the proposed smart fish farm are given in Table 1.

The proposed smart farm structure shown in Fig. 1 can be represented as the flow control model as shown in Fig 2. The flow equations of each tank are given in Eqs. (1)-(4). The flow equation of aquarium tank 1 for the vertical structure is given by Eq. (1) and that of aquarium tank 2 is given by Eq. (2). Also, the flow equation of the RAS tank is expressed by Eq. (3) and that of the balancing tank is expressed as Eq. (4). The rates of water discharge at the inlet and outlet of each tank are different. The water from aquarium tanks 1 and 2 flows into the RAS tank and the flow rate of the RAS tank is determined by the difference in the hydraulic pressure between the aquarium tanks, known as the physical filtration rate.

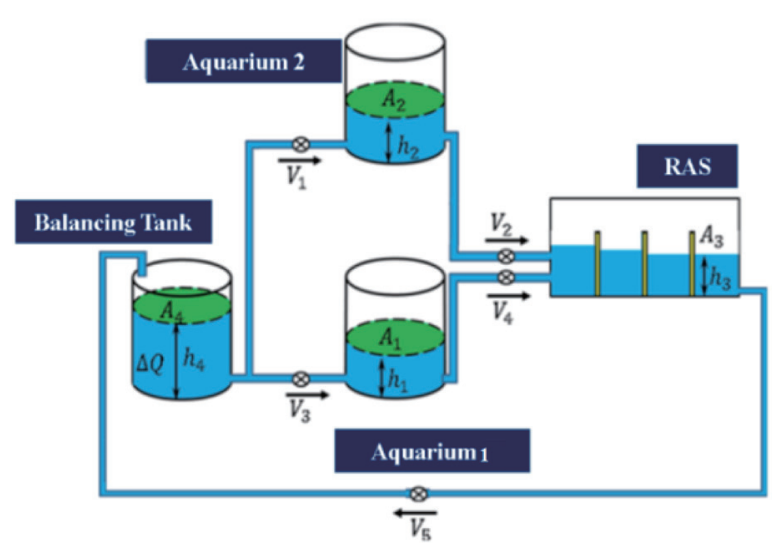

Fig. 2. (Color online) Schematic representation of proposed vertical-type fish aquarium tanks.
Table 1

Specifications of the VRAS.

\begin{tabular}{lcc}
\hline Equipment & $\begin{array}{c}\text { Dimensions } \\
W \times L \times H(\mathrm{~mm})\end{array}$ & $\begin{array}{c}\text { Capacity } \\
\text { (ton) }\end{array}$ \\
\hline Aquarium tank 1 & $900 \times 1600 \times 1000$ & 1.5 \\
Aquarium tank 2 & $900 \times 1600 \times 1000$ & 1.5 \\
RAS tank & $900 \times 1600 \times 1000$ & 1.5 \\
Balancing tank & $900 \times 1600 \times 1000$ & 1.5 \\
Quantity of water & & 4.5 \\
Flow velocity & & $5($ ton $/ \mathrm{h})$ \\
\hline
\end{tabular}




$$
\begin{gathered}
\frac{d h_{1}(t)}{d t}=\frac{\left[\frac{\Delta Q-h_{1}(t)}{V_{1}}-\frac{h_{1}(t)}{V_{2}}\right]}{A_{1}} \\
\frac{d h_{2}(t)}{d t}=\frac{\left[\frac{\Delta Q-h_{2}(t)}{V_{3}}-\frac{h_{2}(t)}{V_{4}}\right]}{A_{2}} \\
\frac{d h_{3}(t)}{d t}=\frac{\left[\frac{\left(h_{1}+h_{2}\right)-h_{3}(t)}{V_{2}+V_{4}}-\frac{h_{3}(t)}{V_{5}}\right]}{A_{3}} \\
\frac{d h_{4}(t)}{d t}=\frac{\left[\frac{h_{3}-h_{4}(t)}{V_{5}}-\frac{h_{4}(t)}{V_{1}+V_{3}}\right]}{A_{4}}
\end{gathered}
$$

$h_{1}, h_{2}, h_{3}$, and $h_{4}$ : heights of aquarium tank 1, aquarium tank 2 , balancing tank, and RAS tank, respectively,

$A_{1}, A_{2}$ : areas of aquarium tank 1 and aquarium tank 2 , respectively $\left[\mathrm{m}^{2}\right]$,

$A_{3}$ : area of RAS tank $\left[\mathrm{m}^{2}\right]$,

$A_{4}$ : area of the balancing tank $\left[\mathrm{m}^{2}\right]$,

$\Delta Q$ : water quantity from balancing tank [ton],

$V_{1}$ : water flow into aquarium tank 1 [ton $\left./ \mathrm{h}\right]$,

$V_{2}$ : water flow from aquarium tank 2 to the RAS tank [ton/h],

$V_{3}$ : water flow into the aquarium tank 1 [ton/h],

$V_{4}$ : water flow from aquarium tank 1 to the RAS tank [ton $\left./ \mathrm{h}\right]$,

$V_{5}$ : water flow from RAS tank [ton/h].

The aquarium tanks should be designed such that solid sludge can be removed easily. As shown in Fig. 3, it is easy to circulate the water and remove the agitated sludge by designing a bottom surface with a conical shape. The inclination angle can determine the rate at which

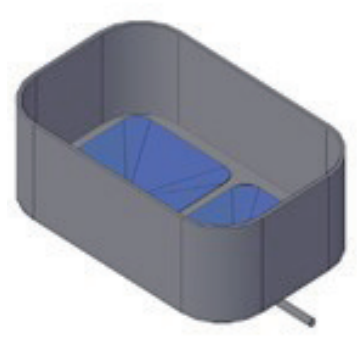

(a)

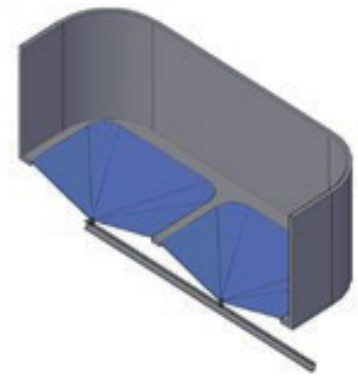

(b)

Fig. 3. (Color online) Aquarium tank for growing eels: (a) sectional view of tank and (b) three-dimensional view of tank. 
water flows out of the tank under gravity. Typically, the tank diameter-to-depth ratio ranges from $5: 1$ to $10: 1$. At this time, considering the fish health, muscle tension, and respiration, the speed of water is determined as a value of 0.5-2.0 times the body length of the fish, which is calculated in one second. The maximum flow rate of the aquarium tank satisfying the optimal growth conditions of the fish is given by Eq. (5). ${ }^{(8)}$

$$
V_{\max }<\left(\frac{5.25}{(L)^{0.37}}\right),
$$

where $V_{\max }$ is the maximum flow rate of the aquarium tank and $L$ is the length of the fish body [m].

The flow velocity force at the center of the conical bottom surface is the rate of water flow in the inner radial direction. This radial direction is caused by the primary flow between the slope of side wall and the bottoms surface. The flow velocity force $F i$ of water discharged at this time is expressed by Eq. (6). It is determined by the difference in the rotational velocity and orifice velocity of flow of water that falls vertically by gravity. ${ }^{(9)}$

$$
F i=\rho Q\left(V_{\text {orif }}-V_{\text {rota }}\right)
$$

where $\rho$ is the density of water $\left[\mathrm{kg} / \mathrm{m}^{3}\right], Q$ the total flow rate $\left[\mathrm{m}^{3} / \mathrm{s}\right], V_{\text {orif }}$ the velocity inlet $[\mathrm{m} / \mathrm{s}]$, and $V_{\text {rota }}$ the rotational velocity $[\mathrm{m} / \mathrm{s}]$.

The RAS tank is designed to improve the water quality in aquarium tanks 1 and 2. During the process of controlling the flow rate of water into each aquarium tank, the water flowing from each aquarium tank flows into the RAS tank. In the RAS tank physical filtration is performed in the first and fourth stages and biological filtration is performed in the second and third stages, as shown in Fig. 4. Physical filtration removes particulate matter and the biological filtration removes ammonia and nitrite, the removed particulate matter and substances are discharged. The flow velocities at this time are given by Eqs. (7) and (8). ${ }^{(10-12)}$

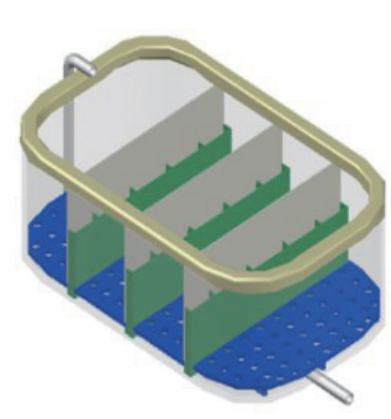

(a)

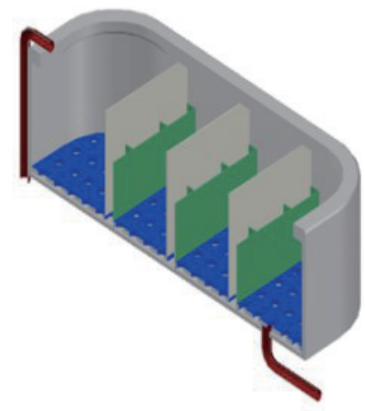

(b)

Fig. 4. (Color online) RAS tank: (a) sectional view and (b) three-dimensional view. 


$$
V=K_{p} S_{1}=K_{p} \frac{h_{f}}{L}
$$

where $V$ is the superficial approach velocity $[\mathrm{m} / \mathrm{s}], K_{p}$ the coefficient of permeability $[\mathrm{m} / \mathrm{s}], S_{1}$ the hydraulic gradient $\left[h_{f} / L\right], h_{f}$ the frictional head loss [m], and $L$ the depth of filters [m].

$$
\frac{h_{f}}{L}=P \frac{v}{g} \frac{(1-\varepsilon)^{2}}{\varepsilon^{3}} V\left(\frac{\sigma_{s}}{d_{p}}\right)^{2}
$$

In this study, ANSYS FLUENT 13.0 software was used for analyzing the fluid flow in the designed tanks. As a result of analyzing the fluid in the tanks in Figs. 3 and 4, it was found that water treatment in a water tank should be carried out at a rate of $10 \mathrm{ton} / \mathrm{h}$. In addition, the circulation filtration process is carried out in four stages and the water treatment capacity is 10 ton/h. Figure 5(a) shows the stream lines of the fluid flow in the aquarium tanks and Fig. 5(b) shows the stream lines of flowing water in the RAS tank.

\section{Experimental Results}

To confirm the real-time monitoring and automatic control performance of the designed sensor system, experiments were conducted on an aquacultural eel farm in the laboratory of the Jangsucheon Ltd. farm on Gangwha Island as shown in Fig. 6(a) and the laboratory of the Institute of Busan University of Foreign Studies as shown in Fig. 6(b). The temperature, DO concentration, $\mathrm{pH}$, and water level sensor data were collected from both locations and stored in a data server of the university laboratory.

The oxy guard DO concentration and water temperature sensor shown in Fig. 7(a) and the $\mathrm{pH}$ sensor shown in Fig. 7(b) were used for the designed system, and the ultrasonic sensor shown in Fig. 7(c) was used to measure the water level of each water tank. The signal conditioner in Fig. 7(d) was used to measure the signal in each water tank and transmit it to the microcomputer control panel.

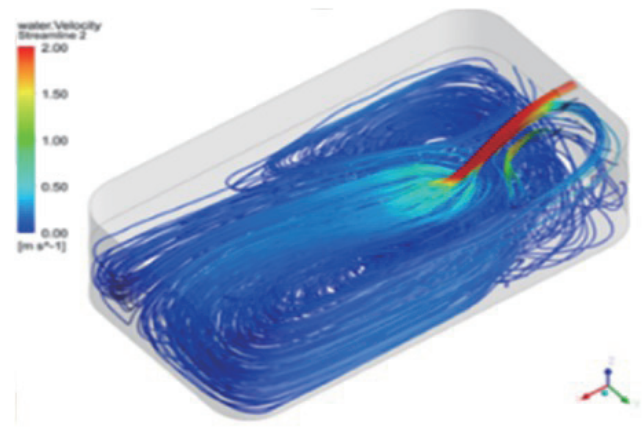

(a)

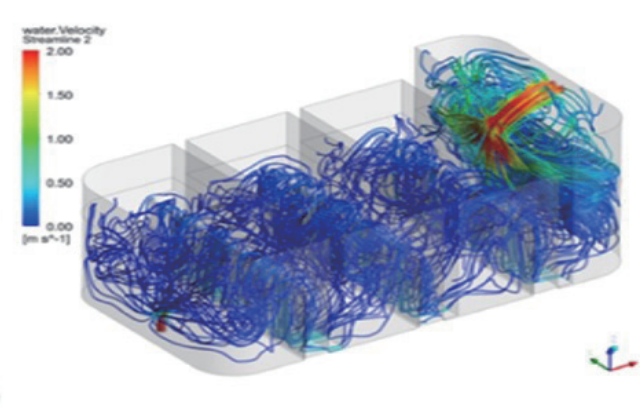

(b)

Fig. 5. (Color online) Simulation result for flow of water: (a) aquarium tanks and (b) RAS tank. 


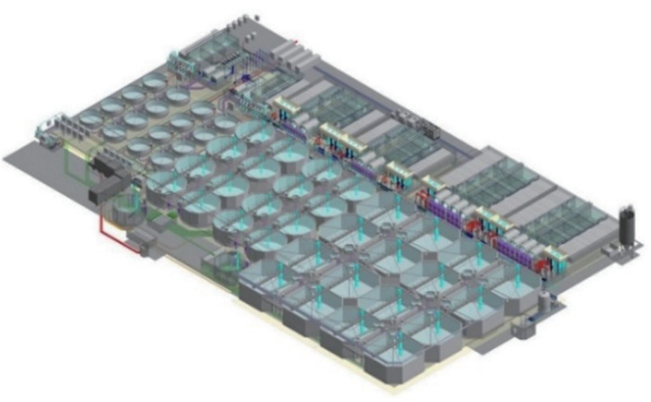

(a)

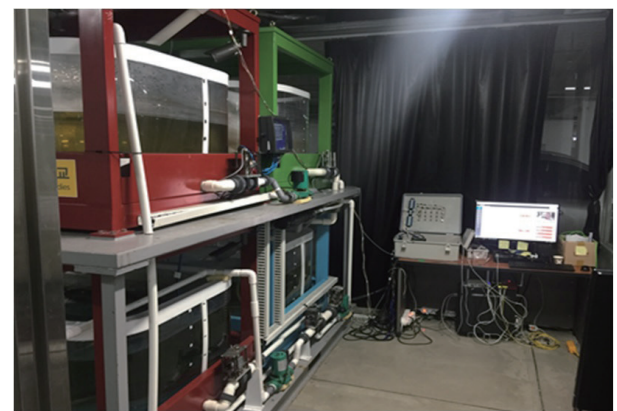

(b)

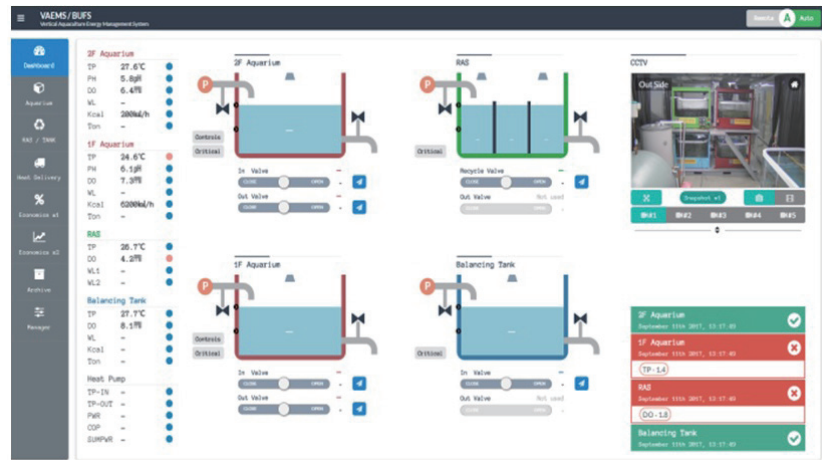

(c)

Fig. 6. (Color online) Smart fish farm: (a) Jangsucheon farm on Ganghwa Island, (b) laboratory of the Institute of BUFS, and (c) monitoring system.

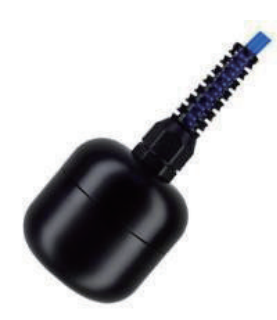

(a)

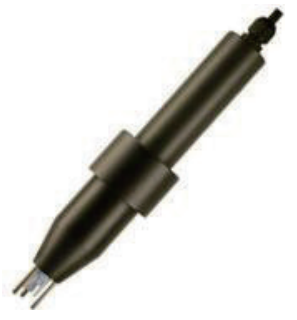

(b)

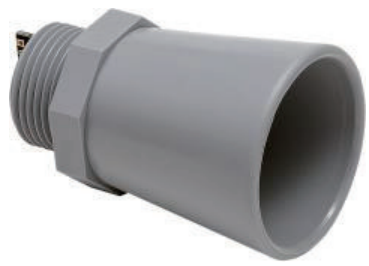

(c)

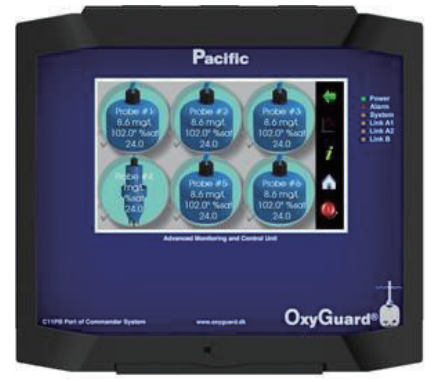

(d)

Fig. 7. (Color online) Sensors used in the experiments: (a) DO concentration and temperature sensors, (b) pH probe, (c) XL-MaxSonar-WR MB7062 ultrasonic sensor, and (d) signal conditioner.

To realize the proposed Smart fish farm system, the automatically controlled electric valve is used as shown in Fig. 8(a). A potentiometer is installed on top of the valve so that the rotational angle of the valve can be measured. In addition, a pump capable of on/off control via a relay is developed as shown in Fig. 8(b). This driving device operates via the control panel signal of the microcomputer and controls the inflow and outflow processing to control the flow rate of each water tank.

The specified operating conditions of the designed aquarium tanks are shown in Table 2. The control algorithm in this experiment was applied to a vertical smart fish farm at Busan 


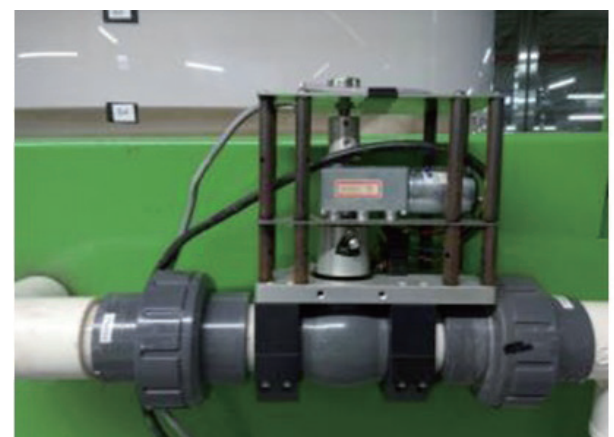

(a)

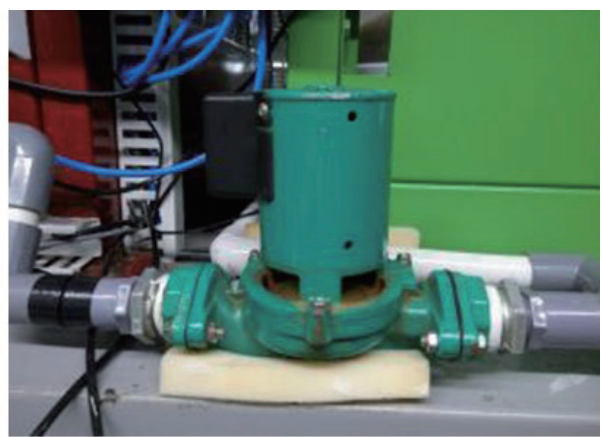

(b)

Fig. 8. (Color online) Automatic water control: (a) electric valve and (b) pump.

Table 2

Operating range of designed smart fish farm.

\begin{tabular}{lccc}
\hline Parameter & Temperature $\left({ }^{\circ} \mathrm{C}\right)$ & Oxygen $(\mathrm{DO})$ concentration $(\mathrm{mg} / \mathrm{L})$ & $\mathrm{pH}$ \\
\hline Operating range & $25-30$ & $6-15$ & $5-9$
\end{tabular}

University of Foreign Studies. Since the water treatment flow control system has a very slow dynamic response, a proportional-integrator-derivative (PID) controller is used as shown in Fig. 8.

To monitor the sensor data, the recorded results of the aquarium tank are displayed on a computer screen as shown in Fig. 9. It is also possible to monitor the growth of eels and the water quality in each tank through various cameras that were installed in the tanks. The balancing water tank is controlled to maintain the temperature of water at 25 to $30{ }^{\circ} \mathrm{C}$ to provide the environment necessary for the optimal growth of eels, and the concentration of DO is adjusted to 6 to $15[\mathrm{mg} / \mathrm{L}]$ by using a blower. In the emergency mode, it is possible to directly control the motorized valve and an additional unit while performing real-time monitoring by switching from the automatic mode to the remote control mode.

Figure 10 shows the result of applying the proposed algorithm to a vertical water tank. Figure 10(a) shows the flow control results of the water tank, Fig. 10(b) shows the DO concentration control, Fig. 10(c) shows the pH control, and Fig. 10(d) shows the water temperature control. By analyzing the experimental results, we confirmed that all of the design target values were satisfied. The graphs in Fig. 10 show that the results are under the specified operating condition as in Table 2.

To confirm the results of this experiment in the field, we conducted automatic control and real-time monitoring of the eel farm of Jangsucheon Ltd. on Ganghwa Island. The pH, DO concentration, and water temperature were monitored using the sensor data as shown in Fig. 11. The experimental results in Fig. 12 show the measured $\mathrm{DO}, \mathrm{pH}$, and water temperature respectively. By analyzing the experimental results, it was confirmed that all controlled values were within the ranges of specified comfort conditions to eels.

Figure 12 shows the graphs plotted for the sensor data taken for $18 \mathrm{~h}$ during the experiment, where the equipment was installed at Jangsucheon. Figure 12(a) shows that the DO concentration sensors gave values ranging from 6 to $15 \mathrm{mg} / \mathrm{L}$, Fig. 12(b) shows pHs ranged 


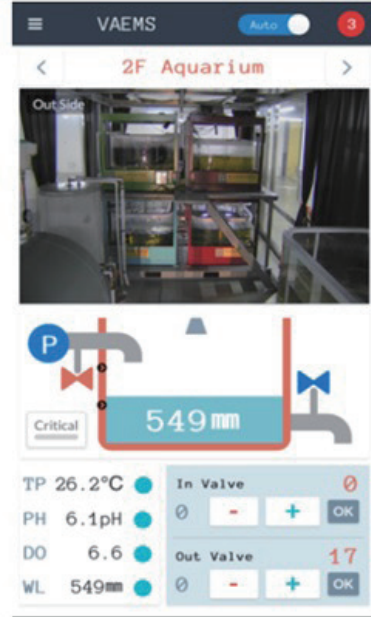

(a)
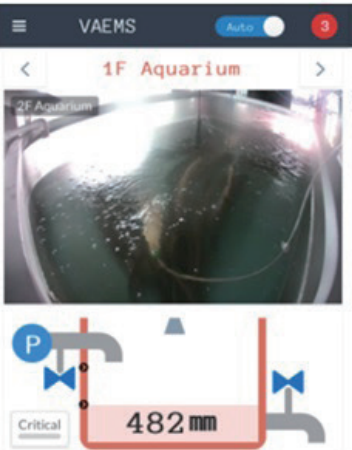

TP $28.8^{\circ} \mathrm{C} \odot$ in valve

$\mathrm{PH} 5.8 \mathrm{pH}$

DO $6.9 \odot$ out valve

$482 m-1+16$

(b)
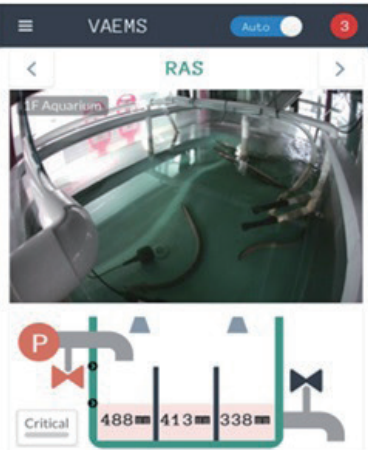

TP $28.4^{\circ} \mathrm{C} \odot$ Recyele valve 0

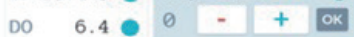

WL1 $488 \mathrm{~mm}$

WL.2 $338 \mathrm{~m}$

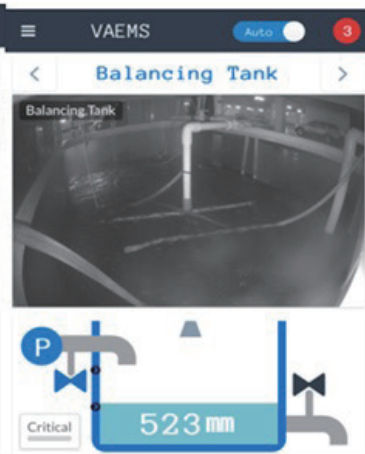

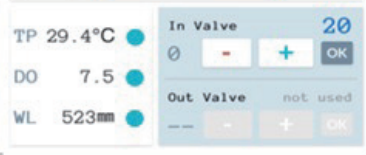

(d)

Fig. 9. (Color online) Display of the measured data obtained from sensors and by monitoring (a) aquarium tank 1, (b) aquarium tank 2, (c) RAS tank, and (d) balancing tank.

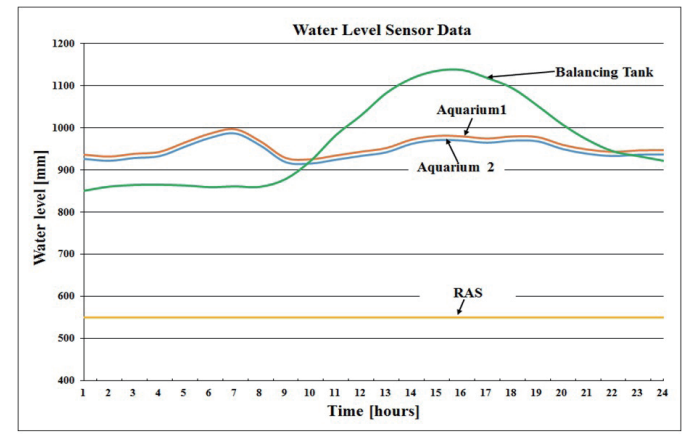

(a)

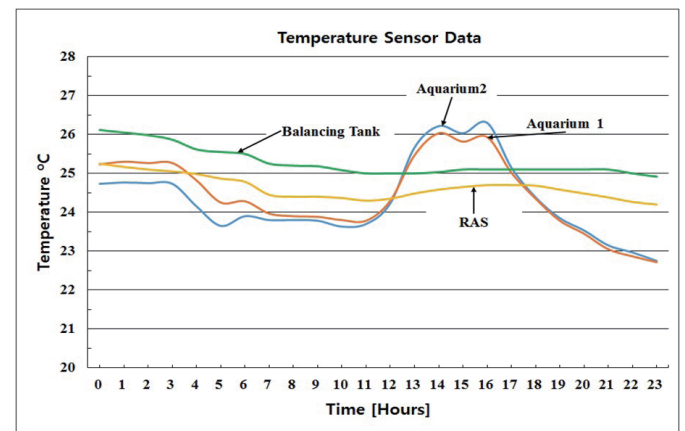

(c)

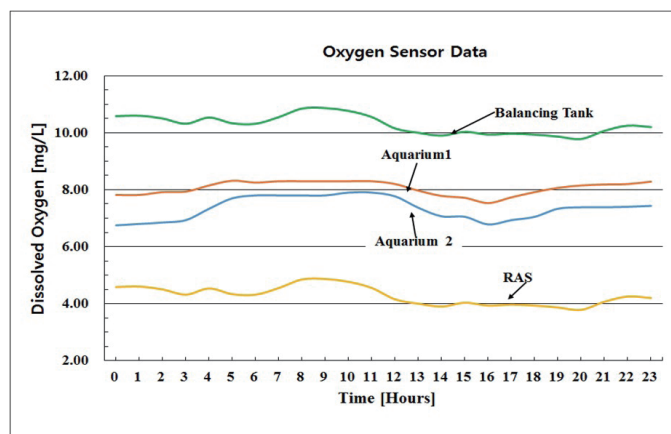

(b)

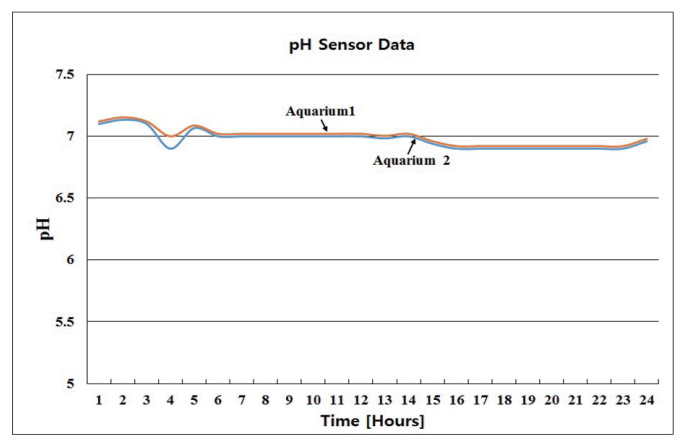

(d)

Fig. 10. (Color online) Experimental results for vertical smart fish in Busan University lab: (a) water level, (b) water temperature, (c) DO concentration, and (d) $\mathrm{pH}$.

from 5 to 9, and Fig. 12(c) shows temperatures ranging from 25 to $35^{\circ} \mathrm{C}$. The sensor data show that the eels were living under optimal growth conditions within the specified operating range. If the readings of the sensors do not match the predefined operating range conditions, feedback 


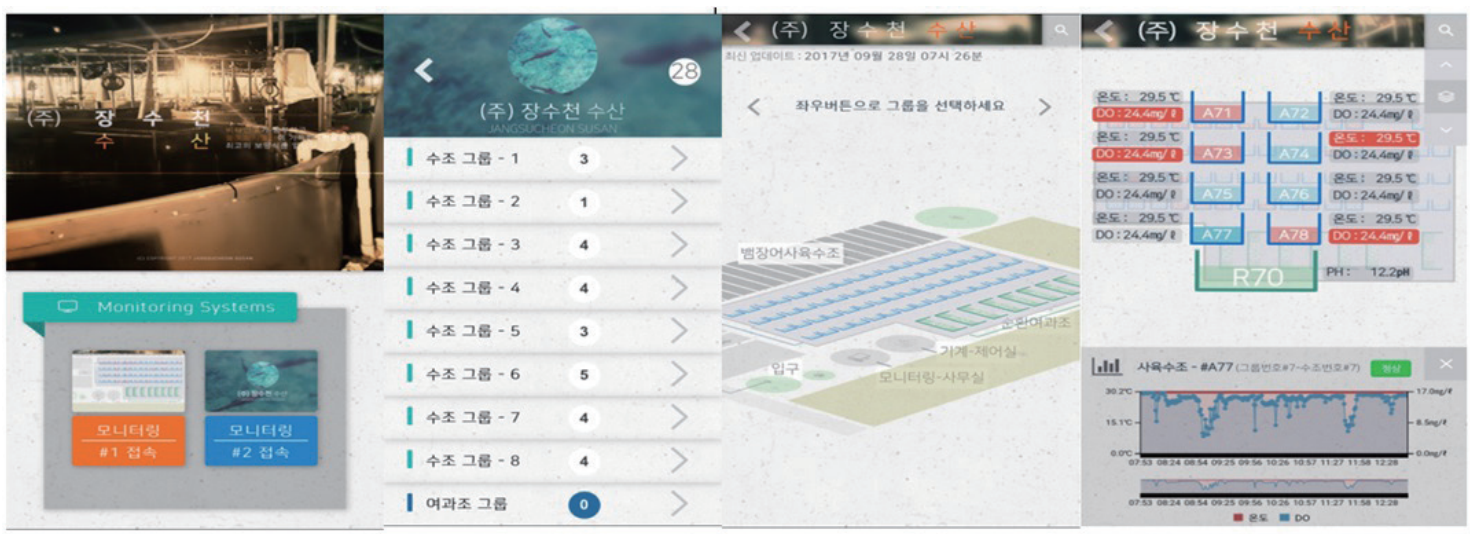

Fig. 11. (Color online) Sensor data monitoring for Jangsucheon Ltd. farm on Ganghwa Island.

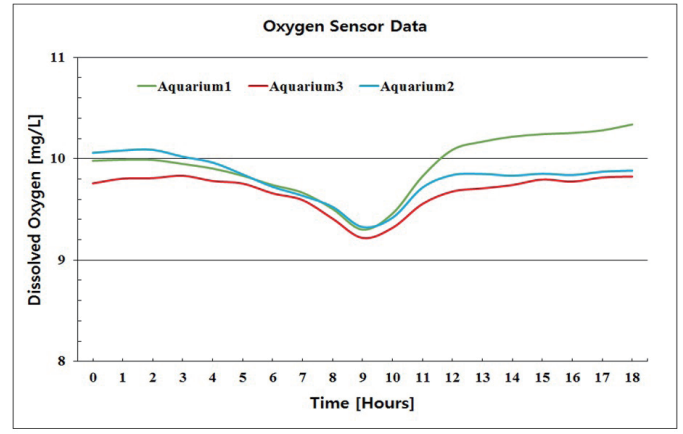

(a)

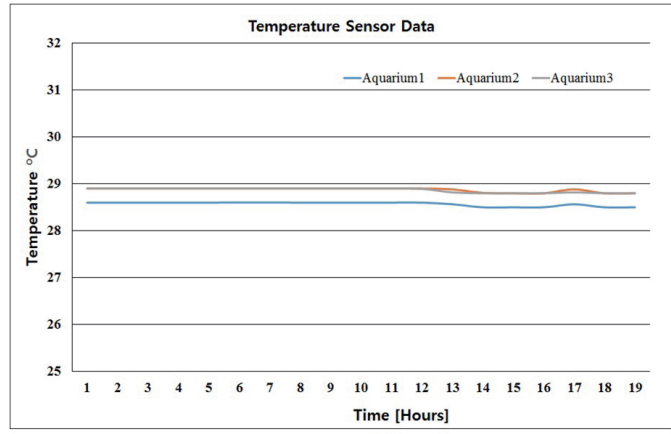

(b)

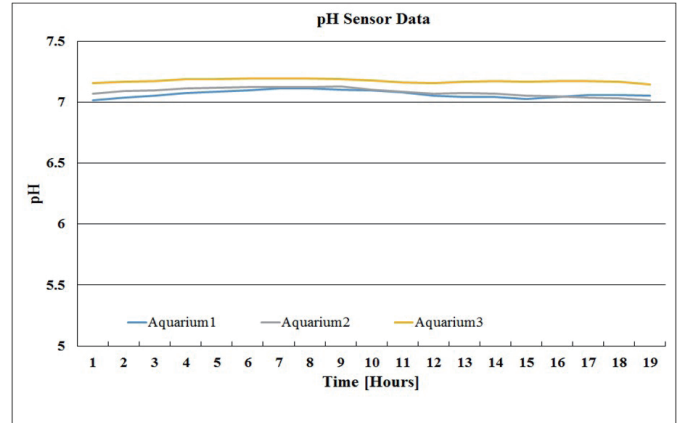

(c)

Fig. 12. (Color online) Experimental results for Jangsucheon horizontal fish farm: (a) DO concentration, (b) water temperature, and (c) $\mathrm{pH}$.

immediately will be sent to the controller to make adjustments according to the signals. For example the healthy growth temperature of eels is from 25 to $30{ }^{\circ} \mathrm{C}$ and if the reading of the sensor shows a temperature of $32{ }^{\circ} \mathrm{C}$, which exceeds this temperature range, then a signal will be transmitted to the balancing tank to reduce the temperature. Hence, this research fulfills the objectives of the proposed IoT-based smart fish farm. 


\section{Conclusion}

As reported in this paper, automatic control and real-time monitoring technology has been developed to realize an IoT-based smart fish farm system. The proposed unit of the IoT-based vertical smart fish farm with automatic control was designed and installed in the laboratory of Future Convergence Technology Research Institute of Busan University of Foreign Studies and the eel culture farm of Changsucheon Ltd. located on Ganghwa Island. The experiments were conducted on both locations, and to control the $\mathrm{pH}$, DO concentration, and temperature of water, ultrasonic sensors were installed in the aquarium tanks. A microcomputer and Raspberrypi were designed, and an electric valve was designed and manufactured as shown in Fig. 8. Experimentally, it was confirmed that the optimal water temperature range was from 25 to $30{ }^{\circ} \mathrm{C}$, the optimal DO concentrations were from 6 to $15[\mathrm{mg} / \mathrm{L}]$, and the optimal pHs were from 5 to 9. The automatic control and real-time monitoring are performed using the sensors, and the measured big data are stored in a server. In the future, using the measured big data from the sensors, we can extend this research to an automatic farm program by deriving the optimal growth conditions of eels through an artificial intelligence program, which is expected to contribute greatly to the domestic and overseas smart farming industry.

\section{Acknowledgments}

This work was supported by the Korea Ministry of Trade, Industry and Energy, under the grant of "Design Expert Training for Factory Automatic of the Based ICT Energy".

\section{References}

1 C. I. M. Martinsab, E. H. Edinga, M. C. J. Verdegema, L. T. N. Heinsbroeka, O. Schneiderc, J. P. Blanchetond, E. R. d'Orbcasteld, and J. A. J. Verretha :Aquacult. Eng. 43 (2010) 83. https://doi.org/10.1016/j.aquaeng.2010.09.002

2 M. P. Masser, J. Rakocy, and T. M. Losordo: SRAC Publication 452 (1999). https://www.researchgate. net/publication/239549714_Recirculating_Aquaculture_Tank_Production_Systems_-_Management_Of_ Recirculating_Systems

3 S. K. Jae and A. V. Angani: 2016 Future Technologies Conf. (IEEE, 2016). https://doi.org/10.1109/ FTC.2016.7821742

4 S. Gong, A. Angani, and K. J. Shin: 2018 Int. Symp. Computer, Consumer and Control (IS3C) (IEEE, 2018). https://doi.org/10.1109/IS3C.2018.00054

5 J.-H. Chen, W.-T. Sung, and G.-Y. Lin: 2015 IEEE Int. Conf. Systems, Man, and Cybernetics (IEEE, 2015). https://doi.org/10.1109/SMC.2015.208

6 H.-C. Lee and K.-H. Ke: IEEE Trans. Instrum. Meas. 67 (2018) 2177. https://doi.org/10.1109/TIM.2018.2814082

7 X. Su, H. Zhang, J. Riekki, A. Keränen, J. K. Nurminen, and L. Du: Procedia Comput. Sci. 32 (2014) 215. https://doi.org/10.1016/j.procs.2014.05.417

8 I. Halachmia, Y. Simonb, R. Guettac, E. M. Hallermand: Aquacult. eng. 32 (2005) 443. https://doi.org/10.1016/ j.aquaeng.2004.09.010

9 M. B. Timmons, S. T. Summerfelt, and B. J. Vinci: Aquacult. Eng. 18 (1998) 51. https://doi.org/10.1016/S01448609(98)00023-5

10 K. J. Shin, A. Angani, and M. Akbar: 2017 Int. Conf. Applied System Innovation (ICASI) (IEEE, 2017). https://doi.org/10.1109/ICASI.2017.7988443

11 K. J. Shin and A. V. Angani: 2017 Int. Conf. Applied System Innovation (ICASI) (IEEE, 2017). https://doi. org/10.1109/ICASI.2017.7988444

12 B. J. Kim and K. J. Shin: J. Inst. Control Rob. Syst. 24 (2018) 155. https://doi.org/10.5302/J.ICROS.2018.17.0214 


\section{About the Authors}

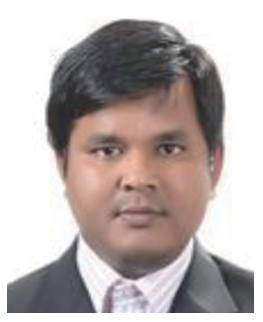

Amarnathvarma Angani is pursuing his Ph.D. degree under the guidance of Professor Kyoo Jae Shin in the Department of ICT Creative Design at Busan University of Foreign Studies (BUFS), Busan, South Korea. He received his master's degree in robotics from the BUFS. He received his B.Tech. degree in mechanical engineering in 2014 from Jawaharlal Nehru Technological University, Kakinada (JNTUK), India, and his diploma in automobile engineering in 2007 from Andhra Polytechnic, Kakinada, India. He had four years of experience as a design engineer in InfoTech Enterprises from 2007 to 2011. His area of research is on smart fish farms. He is also interested in controlling systems, fluid dynamics and thermodynamics, and design.

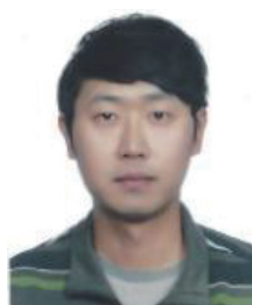

Jun Chan Lee is working on his master's degree in the Department of ICT Creative Design at Busan University of Foreign Studies (BUFS) Busan, South Korea. He received his B.Tech. degree in environmental engineering in 2013 from Korea Maritime and Ocean University (KMOU), Busan, South Korea. $\mathrm{He}$ is working in the field of IT and is interested in object tracking using opencv. He is also into developing web applications.

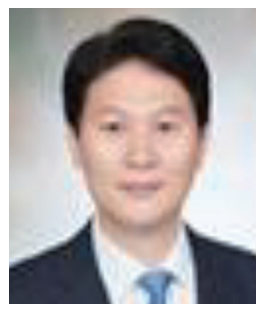

Kyoo Jae Shin is a professor of intelligent robot science at Busan University of Foreign Studies (BUFS), Busan, South Korea. He is the director of the Future Creative Science Research Institute in BUFS. He received his B.S. degree in electronics engineering in 1985 and his M.S degree in electrical engineering from Cheonbuk National University (CNU) in 1988 and his Ph.D. degree in electrical science from the Pusan National University (PNU) in 2009. Dr. Shin was a professor of the Navy Technical Education School. $\mathrm{He}$ is the main director of research associates of the dynamic stabilization system in Dusan Defense Weapon Research Institute. He has also studied and developed a fish robot, a submarine robot, an automatic drug spray robot in a glass room, an automatic milking robot using a manipulator, a personal electrical vehicle, a smart accumulated aquarium using a heat pump, a solar tracking system, a 3D hologram system, and a gun/turret stabilization system. $\mathrm{He}$ is interested in intelligent robots, image signal processing application systems, smart farm, and aquariums using new energy and IoT technology. 